\title{
DISCLOSURE AMBIENTAL: UM ESTUDO DAS DEMONSTRAÇÕES FINANCEIRAS DE EMPRESAS POTENCIALMENTE POLUIDORAS LISTADAS NA BM\&FBOVESPA
}

\section{ENVIRONMENTAL DISCLOSURE: A FINANCIAL STATEMENTS STUDY OF POTENTIALLY POLLUTING COMPANIES LISTED IN BM\&FBOVESPA}

0 trabalho foi apresentado no XVIII ENGEMA - Encontro Internacional sobre Gestão Empresarial e Meio Ambiente realizado da Universidade de São Paulo, dias 5 e 6 de dezembro de 2016.

\section{RESUMO}

As emergentes discussões acerca dos processos de gestão ambiental e social corporificam um desafio para a Contabilidade à medida que as informações tradicionais de caráter econômico e financeiro passam a estar intimamente relacionadas à maneira como as organizações avaliam e gerenciam seus impactos ambientais e sociais, fortalecendo novas práticas de disclosure. Desse modo, e considerando a Lei 10.165/2000, este estudo teve por objetivo analisar se as empresas listadas na BM\&FBovespa que pertencem às atividades potencialmente poluidoras classificadas no $\mathrm{Pp} / \mathrm{Gu}$ como de nível AAlto e Alto estão evidenciando informações ambientais em suas demonstrações financeiras. Fundamentado em uma abordagem de natureza qualitativa e de caráter descritivo, a partir de uma análise documental, o estudo analisou 672 demonstrações, no período de dois anos, de 42 empresas, identificando 1.153 repetições de termos relativos à divulgação de informações de caráter ambiental. As análises evidenciaram que a maior parte de tais informações está presente no Relatório da Administração, e que as demonstrações contábeis mais descritivas possuem maior evidenciação ambiental. Concluiu-se que o disclosure ambiental das empresas atuantes em setores potencialmente poluidores configura prática crescente e em desenvolvimento em que se fazem necessários novos estudos e olhares, visando maior aprofundamento e compreensão.

Palavras chave: Disclosure Ambiental. Demonstrações Contábeis. Gestão Ambiental.

\begin{abstract}
Emerging discussions about the environmental and social management processes embody a challenge for Accounting as traditional information of economic and financial character come to be closely related to how organizations assess and manage their environmental and social impacts, strengthening new practices of disclosure. Thus, considering the Law 10.165 / 2000, this study aims to examine if the companies listed on the BM \& FBOVESPA belonging potentially polluting activities classified in Pp / Gu as Ahigh and high level are showing environmental information in their financial statements. Based on a qualitative approach and descriptive, from a documentary analysis, 672 statements, in a period of two years of 42 companies, were analyzed identifying 1,153 repetitions of terms relating to the dissemination of environmental character information. The analysis showed that most of this information is present in the Management Report, and the more descriptive financial statements have greater environmental disclosure. It is concluded that the environmental disclosure of companies engaged in potentially polluting industries constitutes a growing and developing practice and that further studies and looks are necessary, aiming at further deepening and understanding.
\end{abstract}

Keywords: Environmental Disclosure. Accounting statements. Environmental management.

\begin{abstract}
Karine de Oliveira Ozio
Graduada em Ciências Contábeis pela Universidade Estadual de Londrina (UEL). Contato: Universidade Estadual de Londrina UEL CESA - Centro de Estudos Sociais Aplicados. Contato: Rod Celso Garcia Cid, Km 379, Londrina-PR, CEP: 86051-980. E-mail: kah.0.ozio@gmail.com
\end{abstract}

Octavio Gomes do Carmo

Graduado em Ciências Contábeis pela Universidade Estadual de Londrina (UEL). Contato: Universidade Estadual de Londrina - UEL CESA - Centro de Estudos Sociais Aplicados Rod. Celso Garcia Cid, Km 379, Londrina-PR, CEP: 86051-980 E-mail: octavio_carmo@hotmail.com.

Luciano Gomes dos Reis

Professor Associado do Departamento de Ciências Contábeis, atuando no curso de Mestrado em Administração de Empresas no curso de Graduação em Ciências Contábeis da Universidade Estadual de Londrina. Graduação em Ciências Contábeis pela Universidade Estadual de Londrina (1997), Mestrado em Administração de Empresas pela Universidade Estadual de Maringá (2004) Doutorado em Ciências Contábeis pela Universidade de São Paulo (2008) e Pós-Doutorado em Ciências Contábeis pela FURB (2014). Contato: Universidade Estadual de Londrina - UEL CESA - Centro de Estudos Sociais Aplicados. Rod. Celso Garcia Cid, Km 379, Londrina-PR, CEP: 86051-980. E-mail: lucianoreis@uel.br.

\section{Jaqueline dos Santos Ferrarez}

Docente na Unopar (EaD) e Anhanguera (Ead). Mestrado em Administração pela Universidade Estadual de Londrina (UEL) Graduação em Administração pela Universidade Estadual de Londrina (UEL). Contato: Rua Tietê, 1208, Vila Nova, Londrina, PR CEP 86025-230. E-mail jaque ferrarezi@hotmail com.

Karina Rocha Henriques Gehlen

Professora adjunta na Universidade Positivo e Unifil (EaD). Graduação em Comunicação Social pela Universidade Estadual de Londrina (UEL). Graduação em Ciências Contábeis pela Universidade Estadual de Londrina (UEL). Mestrado em Administração pela Universidade Estadual de Londrina (UEL). Contato: Universidade Estadual de Londrina - UEL CESA - Centro de Estudos Sociais Aplicados. Rod. Celso Garcia Cid, Km 379, Londrina, PR ${ }_{4}$ CEP: 86051-980. E-mail: karina.gehlen@gmail.com. 


\section{INTRODUÇÃO}

A contabilidade se desenvolve de acordo com as necessidades da sociedade e de seus usuários, considerando seu objetivo de fornecer informações contábil-financeiras a respeito da entidade a que se referem essas informações, de modo que sejam úteis para suas partes interessadas, quando da tomada de decisão ligada ao fornecimento de recursos para a organização (CPC 00 R1 - OB2, 2011). Atualmente uma das necessidades é encontrar uma forma de se desenvolver sem agredir o ambiente. A preocupação com a escassez dos recursos naturais está presente nas grandes empresas, pois a indisponibilidade ou ausência destes pode afetar diretamente os fatores produtivos. Desta forma, torna-se necessário controlar os fatores de natureza ambiental.

O controle do fator ambiental é necessário por vários motivos. Um deles é a preocupação com a escassez citada anteriormente. Outro motivo é para evitar eventuais penalidades ou indenizações judiciais, resultantes de atividades operacionais que agridem o meio ambiente. Sendo assim, o controle tronou-se um diferencial para as empresas.

Nesse contexto, tem-se como uma das variáveis que influenciam o tomador de decisão o controle e a preservação dos recursos naturais, que passam a fazer parte das novas exigências do mercado. Clientes, investidores, o governo e a sociedade de modo geral buscam por empresas que possuem diferenciais, e a gestão ambiental pode ser grande atrativo para estes.

Segundo Barbieri (1997) o crescimento da consciência ambiental modifica os padrões de consumo e se torna uma importante arma na defesa do meio ambiente, pois a empresa procura oportunidades por meio dos seus consumidores e, quando estes percebem ações legítimas e verdadeiras, essas ações reforçam a consciência ambiental, criando um círculo virtuoso, no qual uma estratégia mercadológica transforma-se um instrumento de educação ambiental.

No entanto, é preciso que os governos regulem a proteção e conservação do meio ambiente. De acordo com Oliveira, Machado e Beuren (2012) a evidenciação das ações relacionadas à responsabilidade social e à sustentabilidade empresarial deveriam ser inerentes, porém não existe um instrumento em nossa legislação que obrigue as empresas a divulgá-las.

Para evidenciar esta realidade, o trabalho de Ribeiro, Bellen e Carvalho (2011) aponta que existe diferença significativa no nível de evidenciação ambiental nas companhias situadas em países que são mais regulados em relação às práticas de evidenciação ambiental, comparando-se com aqueles que são menos regulados, ressaltando que essas diferenças foram significativas nos itens de divulgação obrigatória. Portanto, confirmam que o disclosure ambiental responde aos estímulos regulatórios de seus países. Com isso, nota-se a importância de políticas ambientais e leis que tratem do tema por parte do governo.

A Lei 10.165/2000 dispõe sobre a Política Nacional do Meio Ambiente. Por meio dela é instituída Taxa de Controle e Fiscalização Ambiental (TCFA), que tem como finalidade regular o poder de polícia concedido ao Instituto Brasileiro do Meio Ambiente e dos Recursos Naturais Renováveis (IBAMA), para controle e fiscalização das atividades potencialmente poluidoras e utilizadoras de recursos naturais. Em seu anexo VIII as atividades são classificadas de acordo com seu Potencial de poluição $(\mathrm{Pp})$ e o Grau de utilização $(\mathrm{Gu})$ dos recursos naturais, sendo que essa escala possui os níveis Pequeno, Médio e Alto. É importante ressaltar que esta lei não possui vínculo contábil, ou seja, ela dispõe sobre a política do meio ambiente, e não sobre normas de contabilidade ambiental.

Diante do exposto e considerando a Lei 10.165/2000, tendo em vista o interesse do controle e a preservação dos recursos naturais que é tendência e faz parte das novas exigências do mercado, surge o interesse de pesquisar sobre a evidenciação de informações ambientais das empresas listadas na Bolsa de Valores, Mercadorias e Futuros (BM\&FBovespa) que se enquadram com nível AAlto e Alto de acordo com a lei citada anteriormente, nos anos de 2014 e 2015.

Assim, a questão a ser respondida neste trabalho é: as empresas listadas na BM\&FBovespa que pertencem às atividades potencialmente poluidoras classificadas no $\mathrm{Pp} / \mathrm{Gu}$ como de nível AAlto e Alto estão evidenciando informações ambientais em suas demonstrações financeiras? Este questionamento norteou o presente estudo que se fundamenta em uma abordagem de natureza qualitativa e de caráter descritivo, a partir de uma análise documental, com o objetivo central de apurar se as empresas que estão classificadas como de alto potencial de poluição estão divulgando em suas demonstrações financeiras informações ambientais, visto que, por serem setores de alto impacto ambiental, torna-se relevante às partes interessadas na obtenção de conhecimento acerca de tais dados.

Considerando as práticas de evidenciação - tanto financeiras quanto ambientais - como um tema cada vez mais presente no âmbito organizacional e discutido na academia, o presente trabalho contribui para a ampliação do conhecimento e compreensão frente aos processos e práticas empresariais voltados à questão ambiental, em especial, quanto às formas de comunicação e de gerenciamento das atividades de empresas pertencentes aos setores de impacto significativo sobre o meio ambiente.

\section{REVISÃO DA LITERATURA}

Este tópico tem por finalidade discutir as principais acepções do Disclosure Ambiental, bem como apresentar pesquisas de caráter relevante realizadas anteriormente a fim de tornar mais bem compreensíveis os temas centrais que ancoram o presente estudo. 


\subsection{Disclosure ambiental}

Segundo Pires e Silveira (2008) o disclosure (evidenciação) é a divulgação das informações pela empresa, de ordem econômica e financeira, com o objetivo de atender não apenas a legislação vigente, como também as necessidades informacionais dos diversos tipos de usuários da informação contábil divulgada. Para Iudícibus (2006, p. 123), "[...] o disclosure está ligado aos objetivos da contabilidade ao garantir informações diferenciadas para os vários tipos de usuários”.

O trabalho de Verrechia (2001) faz uma divisão taxonômica da literatura de divulgação na contabilidade, sugerindo assim três grandes categorias de pesquisa de divulgação. Embora tenha recebido críticas (Dye, 2001) é preciso destacar que, mesmo sendo arbitrária, uma categorização auxilia na organização de um campo de estudos assim como na aplicabilidade de trabalhos empíricos.

A primeira categoria apresentada por Verrechia (2001) é a divulgação baseada em associação, que estuda o efeito da divulgação sobre as ações do investidor. A segunda categoria diz respeito à divulgação baseada no discernimento/julgamento, em que examina como os gestores ou empresas exercitam seus juízos em relação à divulgação das informações sobre as quais eles podem ter conhecimento. Por fim, tem-se a divulgação baseada em eficiência, a qual discute quais modalidades de divulgação têm preferência quando há ausência de conhecimento prévio sobre determinada informação.

Em relação ao papel da contabilidade de fornecer informações úteis para subsidiar as decisões de seus usuários, Pires e Silveira (2008, p.6) citam que "[...] a Contabilidade deve estar atenta às suas necessidades, prestando informações de qualidade e em quantidade suficiente, por meio de suas demonstrações contábeis e complementos".

Nesse sentido, a importância do disclosure se dá pelo acesso à informação. Assim, Pires e Silveira (2008) ainda destacam que a crescente preocupação da sociedade frente à atuação social e ambientalmente responsável das organizações pode ser considerada um novo desafio para a Contabilidade.

A implementação de uma contabilidade socioambiental para complementar a financeira passou a ter divulgação de informações ambientais com características próprias de desenvolvimento e implementação nos anos 1980. Jenkins e Yakovleva (2004) apontam que há diversos papéis na divulgação social e ambiental das empresas: o de avaliar os impactos sociais e ambientais das atividades empresariais; o de medir a eficácia de programas ambientais e de responsabilidade social corporativa; e o de permitir a avaliação global dos recursos corporativos e dos impactos quanto à sustentabilidade mediante a divulgação de relatórios de responsabilidades social e ambiental, bem como por meio de sistemas de informação internos e externos.

Kronbauer e Silva (2012) afirmam que o fato de a entidade divulgar informações ambientais em suas demonstrações revela seu grau de responsabilidade quanto à preservação do ambiente e seu comprometimento perante a sociedade de transmitir os impactos ambientais que suas atividades causam. Entretanto, Braga e Salotti (2008) apontam que um bom ou mau desempenho ambiental pode resultar em complicações no desempenho econômico-financeiro ou no valor da empresa, desta forma, reforça-se a hipótese da relevância da informação contábil de natureza ambiental. "Não se trata de a empresa ser, ou não, ecologicamente correta. A preocupação com a questão ambiental é ética e econômica. Dela depende a permanência da empresa no mercado" (LIMA; VIEGAS, 2002).

Para Rosa et al. (2010), a evidenciação ambiental é formada pelo conjunto de meios utilizados pelas empresas para divulgar suas ações, buscando demonstrar de que maneira a companhia gerencia determinadas atividades em relação ao meio ambiente. Os relatórios anuais possuem um grau de credibilidade maior do que outras mídias corporativas, na medida em que passam por processos de auditoria do mesmo modo que a informação financeira (JENKINS; YAKOVELEVA, 2004; NEU; WARSAME; PEDWELL, 1998).

Partindo do exposto até então, vale ressaltar que o presente trabalho utiliza as informações dos relatórios financeiros promulgados pelas organizações e não de relatórios de sustentabilidade, visto que os relatórios ambientais são de natureza facultativa, enquanto os relatórios financeiros, na medida em que são obrigatórios, apresentam maior conformidade com o objeto da pesquisa.

\subsection{Pesquisas anteriores no campo das práticas de evidenciação ambiental}

Nesta seção, são apresentados os trabalhos anteriores que realizam contribuições à temática de disclosure ambiental, nas mais diferentes abordagens do conhecimento contábil.

Rover, Borba e Murcia (2009) identificaram que, nos três anos analisados, as 57 empresas evidenciaram um total de 6.182 sentenças relacionadas ao meio ambiente, considerando 165 Demonstrações Financeiras e 31 Relatórios de Sustentabilidade analisados. Além disso, percebem um crescimento na evidenciação ambiental ao longo do período, especialmente de 2006 para 2007. Verificaram também que $73 \%$ das informações ambientais são divulgadas nos relatórios e $27 \%$ nas demonstrações financeiras.

Por sua vez, Calixto, Barbosa e Lima (2007) fizeram uma análise da evidenciação ambiental de companhias brasileiras que pertencem aos setores: petroquímica, siderurgia, metalurgia, papel e celulose, energia elétrica, alimentos, transportes, mecânica, saneamento, mineração e têxtil. Os resultados confirmaram o crescimento de informações ambientais, divulgadas por meio dos relatórios contábeis, principalmente no relatório da administração, identificando grandes diferenças entre setores e empresas. Algumas companhias divulgam muitas e outras não divulgam informações sobre evidenciação ambiental. 
Kronbauer e Silva (2012) afirmam que a maioria das informações ambientais se encontram no relatório da administração, correspondendo a $81 \%$. Os autores comentam sobre o fato de o documento não passar por análise de auditoria externa, o que compromete a veracidade das informações; continuam apontando que 95\% dessas informações passam uma boa imagem da empresa, algo que evidencia uma possível omissão de informações que possam denegrir a imagem da companhia, mas estas existem e fazem parte da sua real situação. Ainda no artigo de Kronbauer e Silva (2012) os autores reforçam o fato de não existir obrigatoriedade na divulgação de determinadas informações ambientais e não haver padronização nas informações ambientais divulgadas, o que, conforme ressaltam, acontece principalmente naquelas companhias que se encontram na lista de atividades potencialmente poluidoras e utilizadoras de recursos ambientais conforme a Lei $\mathrm{n}^{\circ} 10.165$, que dispõe sobre a Política Nacional do Meio Ambiente.

O estudo de Fernandes (2013), por outro lado, analisou os relatórios da administração, notas explicativas e os relatórios de informações ambientais no período de 2006 a 2010 de 154 empresas listadas na BM\&FBovespa, sendo essas classificadas de acordo com os critérios da Lei 10.165, que trata da Política Nacional de Meio Ambiente. E concluiu que o ápice da evidenciação ambiental ocorreu em 2008; nesse período, as empresas foram afetadas pela crise financeira e também pela criação da Lei 11.638, fundamentada no trabalho de Alberton, Moletta e Marcon (2011), segundo o qual, em período de crise, quanto maior o nível de informações evidenciadas voluntariamente para os stakeholders, maior a proteção das empresas, fator que poderá alavancar seu valor no mercado.

Raffaelli et al. (2014) verificaram que, em relação ao disclosure ambiental, das 22 empresas analisadas nem todas divulgam as informações ambientais, entre elas 7 não fazem menção a qualquer informação ambiental. Das que divulgam, verificou-se que das 542 sentenças, 351 referem-se a notícias boas, 169 a notícias neutras e 22 a notícias ruins.

A fim de investigar as determinantes que influenciam as divulgações ambientais Silva et al. (2015) coletaram as demonstrações contábeis referentes a 2012 de 43 empresas que estão inseridas nos setores de alto impacto ambiental de acordo com a Lei 10.165/00. Sua conclusão foi que o fato de as empresas serem maiores em vendas não influencia no aumento da quantidade de divulgação de informações ambientais; além disso, as empresas auditadas por Big Four tendem a divulgar mais que as não auditadas, e, por fim, o fato de a empresa ter uma alta rentabilidade não influencia no aumento da quantidade de divulgação.

Outro estudo relevante para o campo foi realizado pelos pesquisadores Carreira, Damião, Abreu e David (2014). Os autores tiveram como objetivo principal compreender os significados atribuídos pelas organizações e seus gestores quanto às práticas de divulgação ambiental, bem como investigar conceitos e indicadores a fim de classificar tal evidenciação como propulsora ou como um desafio à Contabilidade. De maneira geral, o estudo analisou algumas empresas portuguesas e suas divulgações entre os anos 2007 e 2009, concluindo que, embora as evidenciações de caráter ambiental não sejam de fato obrigatórias, o crescente interesse pelo tema implica à Contabilidade responder às expectativas de suas partes interessadas, divulgando informações acerca do meio ambiente de maneira rigorosa. Além disso, os autores também observaram que, mais do que apenas informações de cunho ecológico, com o passar dos anos aumentaram as informações frente aos valores relacionados ao próprio Índice de Divulgação Ambiental elucidando um aumento nas práticas de comunicação ambiental por parte das organizações.

Com a intenção principal de identificar as variáveis de maior impacto no nível das práticas de divulgação ambiental realizadas por empresas de capital aberto da Holanda, os autores Burgwal e Vieira (2014) analisaram uma amostra de 28 companhias as quais representam cerca de $90 \%$ da capitalização do mercado nas bolsas de valores holandesas. A fim de identificar se determinadas ações e impactos ambientais são evidenciados, bem como se as metas organizacionais são alcançadas, os autores selecionaram variáveis e construíram hipóteses frente às relações existentes entre a divulgação ambiental e a lucratividade, a representatividade da indústria e da organização. Em suma, os autores identificaram uma relação proporcional e positiva entre a representatividade do setor e o nível de divulgação ambiental, porém, não foi possível verificar uma mesma relação presente entre a lucratividade e a divulgação ambiental.

Ainda neste contexto, os pesquisadores Nor, Bahari, Adnan, Kamal e Ali (2016), motivados pela possibilidade do alcance da sustentabilidade por parte da Contabilidade, desenvolveram um estudo com o objetivo de investigar as relações existentes entre a divulgação ambiental e o desempenho financeiro organizacional. Foram selecionadas 100 empresas de capital aberto na Malásia no ano de 2011. De maneira geral, os resultados apresentaram dados mistos sobre a existência de práticas de divulgação ambiental relacionadas ao desempenho financeiro, sendo possível verificar que a Contabilidade voltada às questões ambientais está em desenvolvimento, e a busca pelo aprimoramento das práticas de evidenciação ambiental tende a aumentar visto o crescente interesse das sociedades por tais informações.

Neste contexto, vale ressaltar que o presente estudo, diferentemente das pesquisas aqui expressas, está voltado a análises das demonstrações financeiras de organizações de alto potencial poluidor a fim de identificar se tais demonstrações contêm ou não dados de cunho ambiental. Assim, os dados coletados e as análises desenvolvidas não se atêm às influências externas e/ou internas que influenciaram ou não o disclosure, bem como a relação do disclosure com outras variáveis organizacionais e de gestão. Deste modo, o foco consiste na identificação da presença de esclarecimentos prestados à sociedade quanto às práticas empresariais que afetam direta ou indiretamente o meio ambiente e, consequentemente, a sociedade como um todo. 


\section{METODOLOGIA DA PESQUISA}

Considerando o objetivo do presente estudo, o qual consiste em apurar se as empresas estão divulgando informações ambientais em suas demonstrações financeiras, este é classificado como descritivo. Em relação a este tipo de pesquisa, na visão de Beuren e Raupp (2003), caracteriza-se como um estudo intermediário entre a pesquisa exploratória e a explicativa, e, desta forma, não é tão preliminar quanto a primeira, nem tão aprofundado quanto a segunda. Assim, descrever indica identificar, relatar, comparar, entre outros aspectos.

Quanto aos procedimentos de pesquisa, este estudo classifica-se como documental visto que os dados analisados dizem respeito aos documentos referentes às demonstrações financeiras das empresas. Martins e Theóphilo (2009) explicam que a estratégia de pesquisa documental consiste na utilização de documentos como fonte central de dados e evidências. Ressaltam também que as fontes documentais são capazes de evitar certos vieses que poderiam surgir se as informações fossem adquiridas diretamente nas empresas.

A tipologia de pesquisa utilizada na abordagem do problema é classificada como qualitativa, pois de acordo com Richardson (1999) os estudos que utilizam metodologia qualitativa voltam-se à complexidade de determinados problemas, analisando-os a partir da interação de variáveis, compreendendo e classificando processos. O autor ressalta que os estudos qualitativos possibilitam maior nível de aprofundamento e de entendimento de particularidades.

Para estabelecer o processo de seleção das empresas que tiveram as demonstrações financeiras analisadas, foi considerado o anexo VIII da Lei 10.165/2000, como citado no tópico introdutório. No referido anexo, as atividades potencialmente poluidoras são classificadas em determinados níveis. Para fins deste trabalho, foram escolhidas as classificadas nos níveis AAlto e Alto. Considerando-se este critério de seleção, os seguintes setores foram objeto de análise: Extração e Tratamento de Minerais, Indústria Metalúrgica, Indústria de Papel e Celulose, Indústria de Couros e Peles, Indústria Química e Transporte, Terminais, Depósitos e Comércio.

O próximo passo da pesquisa foi verificar, no sítio eletrônico da BM\&FBovespa, quais as empresas listadas praticam as atividades citadas anteriormente. No site foram pesquisadas as companhias listadas por setor de atuação, para em seguida efetuar-se a seleção por segmento. Para a atividade Extração e Tratamento de Minerais foram selecionadas empresas do setor de atuação Petróleo, Gás e Biocombustíveis, segmento Exploração e/ou Refino e setor de atuação Materiais Básicos, segmentos Minerais Metálicos e Minerais não Metálicos; na Indústria Metalúrgica, setor de atuação Materiais básicos, segmentos Artefatos de Cobre, Artefatos de Ferro e Aço e Siderurgia; Indústria de Papel e Celulose, setor de atuação Materiais Básicos, segmento Papel e Celulose; Indústria Química, setor de atuação Materiais Básicos, segmentos Fertilizantes e Defensivos, Petroquímicos e Químicos Diversos; Transporte, Terminais, Depósitos e Comércio, setor de atuação Construção e Transporte, segmento Serviço de Apoio e Armazenagem, Transporte Ferroviário e Transporte Rodoviário. Na seleção foram excluídas as empresas, mesmo listadas no segmento escolhido, cuja atividade produtiva não se enquadra na descrição da lei, por isso a atividade Indústria de Couros e Peles não foi analisada, uma vez que as empresas encontradas não atendem às especificidades do anexo que orienta a escolha.

Foram selecionadas 44 empresas para a análise, sendo 10 da atividade Extração e Tratamento de Minerais, 11 da Indústria Metalúrgica, 6 da Indústria de Papel e Celulose, 11 pertencentes à Indústria Química e 6 empresas de Transporte, Terminais, Depósitos e Comércio. Não foram selecionadas todas as empresas de cada segmento pelo motivo explicado anteriormente, porém o fato de os sites de algumas empresas estarem em manutenção fez com que estas fossem excluídas da lista, visto que sem acesso ao site não seria possível identificar se sua atividade está ou não de acordo com a descrição da lei.

As demonstrações escolhidas para a análise foram: Balanço Patrimonial, Demonstração do Resultado do Exercício, Demonstração das Mutações do Patrimônio Líquido, Demonstração do Valor Adicionado, Demonstração do Resultado Abrangente, Relatório da Administração e Notas Explicativas dos anos 2014 e 2015, totalizando 704 demonstrações.

Quanto à análise dos dados o primeiro passo foi realizar o download das demonstrações de cada empresa, disponíveis no site da BM\&FBovespa. Em seguida, foi feita uma busca por palavras-chave, a fim de facilitar a procura das informações. Tais termos consistiram em: ambiental, sustentabilidade, meio ambiente, preservação, recursos naturais e gestão sustentável. Considerando o objetivo do artigo, o qual foi definido como verificar se as empresas estão divulgando informações de natureza ambiental, considerou-se que as palavras 'ambiental', 'meio ambiente' e 'recursos naturais' estavam diretamente relacionadas ao objetivo da pesquisa. De forma suplementar, as palavras 'sustentabilidade', 'preservação' e 'gestão sustentável' foram selecionadas, pois de acordo com a literatura da área de divulgação ambiental (ROSA et al., 2010; GODOI, 2011; FERNANDES, 2013; SILVA, 2015) podem estar relacionadas aos aspectos de divulgação ambiental, dentro de determinado contexto. Após a localização das palavras, foi feita a leitura do parágrafo em que foram encontradas, para certificação de que estão relacionadas ao contexto desejado. Mesmo quando não foi localizada nenhuma das palavras-chave na demonstração, foi feita a leitura do relatório da administração, pois existem outras opções de palavras além das que foram selecionas; desta forma tem-se maior confiabilidade de que todas foram analisadas.

Após a seleção, para tabulação das informações, o contexto foi verificado mediante análise de conteúdo (Bardin, 1977), sendo utilizada a análise primária, que consiste na seleção de palavras por intermédio da interpretação das mensagens emitidas nos documentos analisados, para posterior tabulação e construção das análises. 


\section{APRESENTAÇÃO E ANÁLISE DOS DADOS}

Das empresas descritas na metodologia da pesquisa foram excluídas 2 para os processos de análise, sendo 1 da atividade Extração e Tratamento de Minerais e 1 da Indústria Metalúrgica. O motivo da exclusão consiste no fato de as empresas selecionadas participarem do mesmo grupo. No momento da contagem das empresas que seriam analisadas, estas não tinham sido excluídas da lista e por isso ficaram na soma. Considerando tais alterações, o número de demonstrações analisadas passa a ser 672 .

Quanto à coleta de dados, as demonstrações foram baixadas do sítio eletrônico da BM\&FBovespa como arquivos compactados e, posteriormente, foram importados para o programa 'Empresas Net' (cujo download está disponível no mesmo sítio), para que pudessem ser salvos então no formato PDF, facilitando os procedimentos de coleta de informações. Como exemplo, a demonstração Balanço Patrimonial é disponibilizada em duas partes, o Balanço Patrimonial Ativo e Balanço Patrimonial Passivo, e a partir da utilização deste programa torna-se possível salvar ambas as partes em um mesmo arquivo, permitindo o acesso aos dados de modo prático.

A coleta de dados foi efetuada por meio da pesquisa das palavras-chave descritas no tópico metodológico, e com execução nos documentos disponibilizados pelas empresas no sitio da BM\&FBovespa. Na coleta foram consideradas também as variáveis das palavras, por exemplo, para a palavra ambiental foram consideradas variáveis como ambientais e ambientalmente.

As informações encontradas foram dispostas em planilhas organizadas por empresa e em seguida agrupadas por setor. Os quadros a seguir apresentam os dados obtidos:

Quadro 1: Termo 'Ambiental'

\begin{tabular}{|c|c|c|c|c|c|c|c|c|c|c|c|c|}
\hline \multirow{3}{*}{ Demonstrações } & \multicolumn{10}{|c|}{ Setor } & \multirow{2}{*}{\multicolumn{2}{|c|}{ Total }} \\
\hline & \multicolumn{2}{|c|}{ Extração } & \multicolumn{2}{|c|}{ Metalúrgica } & \multicolumn{2}{|c|}{ Papel } & \multicolumn{2}{|c|}{ Química } & \multicolumn{2}{|c|}{ Transporte } & & \\
\hline & 2014 & 2015 & 2014 & 2015 & 2014 & 2015 & 2014 & 2015 & 2014 & 2015 & 2014 & 2015 \\
\hline BP & 2 & 2 & 4 & 5 & 0 & 0 & 4 & 4 & 0 & 0 & 10 & 11 \\
\hline DRE & 0 & 0 & 0 & 0 & 0 & 0 & 0 & 0 & 0 & 0 & 0 & 0 \\
\hline DRA & 0 & 0 & 0 & 0 & 0 & 0 & 0 & 0 & 0 & 0 & 0 & 0 \\
\hline $\mathrm{DFC}$ & 0 & 0 & 1 & 1 & 0 & 0 & 0 & 0 & 0 & 0 & 1 & 1 \\
\hline DMPL & 0 & 0 & 0 & 0 & 0 & 0 & 0 & 0 & 0 & 0 & 0 & 0 \\
\hline DVA & 0 & 0 & 0 & 0 & 0 & 0 & 0 & 0 & 0 & 0 & 0 & 0 \\
\hline $\mathrm{RA}$ & 38 & 35 & 17 & 15 & 39 & 44 & 37 & 33 & 6 & 7 & 137 & 134 \\
\hline NE & 71 & 75 & 52 & 53 & 10 & 9 & 30 & 36 & 23 & 22 & 186 & 195 \\
\hline TOTAL & 111 & 112 & 74 & 74 & 49 & 53 & 71 & 73 & 29 & 29 & 334 & 341 \\
\hline
\end{tabular}

Fonte: Elaborado pelos autores.

Analisando os resultados encontrados quanto ao termo ambiental, nota-se que no ano de 2015 a divulgação de informações ambientais foi maior em relação ao ano de 2014 - o que pode indicar um aumento do disclosure com o passar do tempo.

Verifica-se que o setor que evidencia o maior número de vezes o termo ambiental em suas demonstrações é o de Extração e Tratamento de Minerais com 111 termos encontrados em 2014 e 112 em 2015, seguido pelo setor de Indústria Metalúrgica. Considerando que estes mesmo setores são citados no anexo VIII da Lei 10.165 como de nível AAlto - indicando então que estes são os setores com maior Potencial de Poluição e Grau de Utilização dos recursos naturais - pode-se inferir que as empresas que mais agridem o meio ambiente preocupam-se em informar aos seus usuários externos os fatos ocorridos e/ou medidas adotadas com relação ao ambiente natural.

Quadro 2: Termo 'Sustentabilidade'

\begin{tabular}{|c|c|c|c|c|c|c|c|c|c|c|c|c|}
\hline \multirow{3}{*}{ Demonstrações } & \multicolumn{10}{|c|}{ Setor } & \multirow{2}{*}{\multicolumn{2}{|c|}{ Total }} \\
\hline & \multicolumn{2}{|c|}{ Extração } & \multicolumn{2}{|c|}{ Metalúrgica } & \multicolumn{2}{|c|}{ Papel } & \multicolumn{2}{|c|}{ Química } & \multicolumn{2}{|c|}{ Transporte } & & \\
\hline & 2014 & 2015 & 2014 & 2015 & 2014 & 2015 & 2014 & 2015 & 2014 & 2015 & 2014 & 2015 \\
\hline BP & 0 & 0 & 0 & 0 & 0 & 0 & 0 & 0 & 0 & 0 & 0 & 0 \\
\hline DRE & 0 & 0 & 0 & 0 & 0 & 0 & 0 & 0 & 0 & 0 & 0 & 0 \\
\hline DRA & 0 & 0 & 0 & 0 & 0 & 0 & 0 & 0 & 0 & 0 & 0 & 0 \\
\hline $\mathrm{DFC}$ & 0 & 0 & 0 & 0 & 0 & 0 & 0 & 0 & 0 & 0 & 0 & 0 \\
\hline DMPL & 0 & 0 & 0 & 0 & 0 & 0 & 0 & 0 & 0 & 0 & 0 & 0 \\
\hline DVA & 0 & 0 & 0 & 0 & 0 & 0 & 0 & 0 & 0 & 0 & 0 & 0 \\
\hline $\mathrm{RA}$ & 21 & 21 & 15 & 5 & 40 & 50 & 46 & 33 & 15 & 9 & 137 & 118 \\
\hline $\mathrm{NE}$ & 5 & 4 & 3 & 3 & 5 & 4 & 0 & 0 & 2 & 2 & 15 & 13 \\
\hline TOTAL & 26 & 25 & 18 & 8 & 45 & 54 & 46 & 33 & 17 & 11 & 152 & 131 \\
\hline
\end{tabular}

Fonte: Elaborado pelos autores. 
Sustentabilidade é o segundo termo mais encontrado na coleta de dados, sendo maior a divulgação no ano de 2014, com 152 palavras localizadas. A demonstração que contém o maior número de palavras quanto à sustentabilidade é o Relatório da Administração. Por meio da análise de conteúdo realizada, verificou-se que na maior parte das vezes em que o termo sustentabilidade foi encontrado, estava relacionado a políticas, projetos e medidas das empresas. Este fato justifica a razão de o termo estar presente no Relatório da Administração e Notas Explicativas, e não nas demais demonstrações, uma vez que estas são mais descritivas.

Diferentemente do resultado encontrado anteriormente, o termo teve maior divulgação no setor de Indústria de Papel e Celulose. Este resultado se dá pelo fato de que estas empresas evidenciam as medidas tomadas frente às práticas de reflorestamento.

Quadro 3: Termo ‘Meio Ambiente’

\begin{tabular}{|c|c|c|c|c|c|c|c|c|c|c|c|c|}
\hline \multirow{3}{*}{ Demonstrações } & \multicolumn{10}{|c|}{ Setor } & \multirow{2}{*}{\multicolumn{2}{|c|}{ Total }} \\
\hline & \multicolumn{2}{|c|}{ Extração } & \multicolumn{2}{|c|}{ Metalúrgica } & \multicolumn{2}{|c|}{ Papel } & \multicolumn{2}{|c|}{ Química } & \multicolumn{2}{|c|}{ Transporte } & & \\
\hline & 2014 & 2015 & 2014 & 2015 & 2014 & 2015 & 2014 & 2015 & 2014 & 2015 & 2014 & 2015 \\
\hline $\mathrm{BP}$ & 0 & 0 & 0 & 0 & 0 & 0 & 0 & 0 & 0 & 0 & 0 & 0 \\
\hline DRE & 0 & 0 & 0 & 0 & 0 & 0 & 0 & 0 & 0 & 0 & 0 & 0 \\
\hline DRA & 0 & 0 & 0 & 0 & 0 & 0 & 0 & 0 & 0 & 0 & 0 & 0 \\
\hline DFC & 0 & 0 & 0 & 0 & 0 & 0 & 0 & 0 & 0 & 0 & 0 & 0 \\
\hline DMPL & 0 & 0 & 0 & 0 & 0 & 0 & 0 & 0 & 0 & 0 & 0 & 0 \\
\hline DVA & 0 & 0 & 0 & 0 & 0 & 0 & 0 & 0 & 0 & 0 & 0 & 0 \\
\hline RA & 13 & 12 & 10 & 9 & 6 & 8 & 16 & 15 & 8 & 7 & 53 & 51 \\
\hline $\mathrm{NE}$ & 7 & 5 & 2 & 4 & 3 & 3 & 2 & 1 & 8 & 6 & 22 & 19 \\
\hline TOTAL & 20 & 17 & 12 & 13 & 9 & 11 & 18 & 16 & 16 & 13 & 75 & 70 \\
\hline
\end{tabular}

Fonte: Elaborado pelos autores.

O termo Meio Ambiente, assim como Sustentabilidade teve sua maior divulgação no ano de 2014, sendo localizado 75 vezes, e a maior parte da divulgação encontra-se no Relatório da Administração.

$\mathrm{O}$ fato de o termo Meio Ambiente estar mais presente no relatório, se comparado às demais demonstrações, se deve à sua utilização para divulgar as políticas, projetos e medidas da empresa para preservação do meio ambiente. Tal fato é comprovado ao analisar as palavras encontradas nas Notas Explicativas. Nesta demonstração foram verificados os gastos e reservas que as empresas possuem para conservação da natureza.

Quadro 4: Termo 'Preservação’

\begin{tabular}{|c|c|c|c|c|c|c|c|c|c|c|c|c|}
\hline \multirow{3}{*}{ Demonstrações } & \multicolumn{10}{|c|}{ Setor } & \multirow{2}{*}{\multicolumn{2}{|c|}{ Total }} \\
\hline & \multicolumn{2}{|c|}{ Extração } & \multicolumn{2}{|c|}{ Metalúrgica } & \multicolumn{2}{|c|}{ Papel } & \multicolumn{2}{|c|}{ Química } & \multicolumn{2}{|c|}{ Transporte } & & \\
\hline & 2014 & 2015 & 2014 & 2015 & 2014 & 2015 & 2014 & 2015 & 2014 & 2015 & 2014 & 2015 \\
\hline BP & 0 & 0 & 0 & 0 & 0 & 0 & 0 & 0 & 0 & 0 & 0 & 0 \\
\hline DRE & 0 & 0 & 0 & 0 & 0 & 0 & 0 & 0 & 0 & 0 & 0 & 0 \\
\hline DRA & 0 & 0 & 0 & 0 & 0 & 0 & 0 & 0 & 0 & 0 & 0 & 0 \\
\hline DFC & 0 & 0 & 0 & 0 & 0 & 0 & 0 & 0 & 0 & 0 & 0 & 0 \\
\hline DMPL & 0 & 0 & 0 & 0 & 0 & 0 & 0 & 0 & 0 & 0 & 0 & 0 \\
\hline DVA & 0 & 0 & 0 & 0 & 0 & 0 & 0 & 0 & 0 & 0 & 0 & 0 \\
\hline RA & 0 & 0 & 2 & 0 & 2 & 4 & 1 & 3 & 1 & 2 & 6 & 9 \\
\hline $\mathrm{NE}$ & 0 & 0 & 1 & 0 & 4 & 3 & 0 & 0 & 0 & 0 & 5 & 3 \\
\hline TOTAL & 0 & 0 & 3 & 0 & 6 & 7 & 1 & 3 & 1 & 2 & 11 & 12 \\
\hline
\end{tabular}

Fonte: Elaborado pelos autores.

Preservação é o termo analisado que apresentou a menor quantidade de resultados na coleta de dados, sendo localizado apenas 11 vezes no ano de 2014 e 12 no ano de 2015. Assim como os termos Sustentabilidade e Meio Ambiente, Preservação apresentou o maior número de ocorrência no Relatório da Administração, pois também é utilizado para divulgar políticas, projetos e medidas adotadas pelas empresas. 
Quadro 5: Termo 'Recursos Naturais'

\begin{tabular}{|c|c|c|c|c|c|c|c|c|c|c|c|c|}
\hline \multirow{3}{*}{ Demonstrações } & \multicolumn{10}{|c|}{ Setor } & \multirow{2}{*}{\multicolumn{2}{|c|}{ Total }} \\
\hline & \multicolumn{2}{|c|}{ Extração } & \multicolumn{2}{|c|}{ Metalúrgica } & \multicolumn{2}{|c|}{ Papel } & \multicolumn{2}{|c|}{ Química } & \multicolumn{2}{|c|}{ Transporte } & & \\
\hline & 2014 & 2015 & 2014 & 2015 & 2014 & 2015 & 2014 & 2015 & 2014 & 2015 & 2014 & 2015 \\
\hline $\mathrm{BP}$ & 0 & 0 & 0 & 0 & 0 & 0 & 0 & 0 & 0 & 0 & 0 & 0 \\
\hline DRE & 0 & 0 & 0 & 0 & 0 & 0 & 0 & 0 & 0 & 0 & 0 & 0 \\
\hline DRA & 0 & 0 & 0 & 0 & 0 & 0 & 0 & 0 & 0 & 0 & 0 & 0 \\
\hline DFC & 0 & 0 & 0 & 0 & 0 & 0 & 0 & 0 & 0 & 0 & 0 & 0 \\
\hline DMPL & 0 & 0 & 0 & 0 & 0 & 0 & 0 & 0 & 0 & 0 & 0 & 0 \\
\hline DVA & 0 & 0 & 0 & 0 & 0 & 0 & 0 & 0 & 0 & 0 & 0 & 0 \\
\hline RA & 1 & 0 & 0 & 1 & 3 & 4 & 0 & 0 & 0 & 1 & 4 & 6 \\
\hline $\mathrm{NE}$ & 7 & 8 & 0 & 0 & 0 & 0 & 1 & 1 & 0 & 0 & 8 & 9 \\
\hline TOTAL & 8 & 8 & 0 & 1 & 3 & 4 & 1 & 1 & 0 & 1 & 12 & 15 \\
\hline
\end{tabular}

Fonte: Elaborado pelos autores.

O termo Recursos Naturais teve sua maior divulgação no ano de 2015, com 15 termos encontrados, estando localizado nas Notas Explicativas. Analisando o conteúdo, constatou-se que, em sua maioria, o termo foi utilizado para evidenciar gastos com exploração de recursos naturais por empresa do setor de Extração e Tratamento de Minerais. Seu uso no Relatório da Administração, assim como outros termos, foi para divulgar políticas, projetos e medidas de preservação.

Na seção metodológica deste estudo, o termo 'Gestão Sustentável' foi apontado como um dos que seriam coletados para a análise. A coleta foi realizada, porém, não apresentou resultados, sendo então desconsiderado. Vale ressaltar que o fato de o termo não constar nas demonstrações não significa que as empresas não possuam uma gestão sustentável, uma vez que é possível elucidá-la a partir da utilização de outros termos. Tal afirmação pode se inferir da própria análise, considerando que, por vezes, os termos citados anteriormente são utilizados justamente para divulgar políticas, projetos e medidas ambientais que concedem à organização uma gestão de caráter sustentável.

De acordo com os resultados apresentados, verifica-se que as empresas destacam as suas informações de natureza ambiental essencialmente nos relatórios de administração, que se constituem em documentos que expressam muitas vezes, única e exclusivamente, a visão dos gestores da empresa, ressaltando-se aspectos positivos da realidade, na visão destes.

Considera-se que a presente pesquisa apresenta como principal contribuição científica a demonstração de que, nas empresas com alto potencial de poluição, há ênfase na divulgação das informações de natureza ambiental nos relatórios de administração, sendo que nos demais relatórios contábeis, com exceção do termo 'ambiental', não há divulgações de natureza relevante nas demais demonstrações, mesmo podendo haver impactos nos lucros da empresa, nos fluxos de caixa e na forma de distribuição do valor adicionado, em virtude de questões de natureza ambiental.

Como contribuição prática, espera-se que, a partir da apresentação da discussão a respeito de como as empresas devem divulgar suas informações ambientais, e todos os seus reflexos, diretos e indiretos, haja maior conscientização e visualização de como as informações de natureza ambiental, em especial nas empresas potencialmente poluidoras, podem afetar o processo de tomada de decisão por parte de usuários internos e externos às organizações.

\section{CONCLUSÃO DA PESQUISA}

O objetivo do presente trabalho consistiu em apurar se as empresas classificadas como de alto potencial de poluição estão divulgando em suas demonstrações financeiras informações ambientais. Sendo assim, esta pesquisa atingiu seu objetivo na medida em que analisou 672 demonstrações de 42 empresas, no período de dois anos. Obteve-se como resultado 1.153 repetições de termos relativos à divulgação de informações ambientais.

As análises evidenciaram que a maior parte das informações é divulgada no Relatório da Administração, sendo $56,8 \%$ dos termos localizados, em um total de 655 termos. Quanto às informações divulgadas nesta demonstração, verificou-se que em sua maioria as informações apresentadas relatam a respeito de políticas, projetos e medidas adotados pela empresa. As informações localizadas nas Notas Explicativas representam 41,2\% dos termos coletados, em um total de 475 termos. Quanto a esta demonstração, verificou-se que as informações nela divulgadas referem-se a políticas e medidas adotadas pela empresa, porém estas não dizem respeito apenas a práticas administrativas, mas também contábeis, por exemplo, provisões ambientais que foram criadas.

Quanto aos termos utilizados, constatou-se que Ambiental foi o que apresentou o maior número de resultados. Além disso, relatou-se que foi o único divulgado em outras demonstrações, além de Relatório da Administração e Notas Explicativas - sendo estas Balanço Patrimonial e Demonstração dos Fluxos de Caixa. Este fato pode estar relacionado à razão de demonstrações menos descritivas apresentarem o nome das contas utilizadas, como Passivos Ambientas e 
Provisões Ambientais. Por este motivo, é possível que os demais termos não tenham sido localizados, uma vez que não foram encontradas contas contábeis com as palavras sustentabilidade, meio ambiente, preservação, recursos naturais, nem suas variáveis - sendo estas utilizadas em sua maioria para descrever os atos e fatos.

De maneira geral, espera-se que este trabalho contribua para os estudos relativos à contabilidade ambiental na medida em que retrata a crescente inserção de informações de cunho ambiental em demonstrações empresariais, e até então de caráter estritamente econômico, permitindo compreender melhor um contexto organizacional permeado por mudanças quanto às práticas de comunicação com suas partes interessadas. Sugere-se que em pesquisas futuras estes setores potencialmente poluidores sejam novamente analisados, a fim de que se torne possível acompanhar o desenvolvimento do disclosure ambiental nas empresas pertencentes a este grupo, bem como analisar a partir de diferentes olhares as variáveis que implicam evoluções em tais práticas de evidenciação. Desta forma, será possível verificar as modificações ocorridas ao longo do tempo e possíveis implicações na Contabilidade como um todo frente ao seu papel de divulgar o resultado das atividades empresariais e seus impactos no meio social e ambiental, acompanhando as transformações das sociedades contemporâneas.

\section{REFERENCIAS}

ALBERTON, Anete: MOLETTA, Antônio Miguel Cavalheiro; MARCON, Rosilene. Os Níveis Diferenciados de Governança Corporativa Blindam as Firmas contra Crises Financeiras? Uma Análise da Crise Financeira de 2008. Pensar Contábil, Rio de Janeiro, v. 13, n. 51, p. 56 - 64, maio/ago. 2011.

BARBIERI, J. C. Competitividade Internacional e Normatização Ambiental. In: IV Encontro Nacional sobre Gestão Empresarial e Meio Ambiente. Anais... São Paulo, nov. 1997.

BARDIN, L. Análise de conteúdo. Lisboa: Edições 70, 1977.

BEUREN, I. M.; RAUPP, F. M. Metodologia da Pesquisa Aplicável às Ciências Sociais. In: BEUREN, I. M. (Org.). Como Elaborar Trabalhos Monográficos em Contabilidade: Teoria e Prática. São Paulo: Atlas, p. 76-97, 2003.

BM\&FBOVESPA. Empresas Listadas. Disponível em: <http://www.bmfbovespa.com.br/ciaslistadas/empresaslistadas/BuscaEmpresaListada.aspx?Idioma=pt-br>. Acesso em: 16 abr. 2015.

BRAGA, J. P.; SALOTTI, B. M. Relação entre nivel de disclosure ambiental e características corporativas de empresas no Brasil. 2008. Disponível em: <http://www.congressousp.fipecafi.org/web/artigos82008/180.pdf>. Acesso: 13 jan. 2016.

BRASIL. Lei 10.165 de 27 de dezembro de 2000. Altera a Lei nº. 6.938, de 31 de agosto de 1981, que dispõe sobre a Política Nacional do Meio Ambiente, seus fins e mecanismos de formulação e aplicação, e dá outras providências. Disponível em: <http://www.planalto. gov.br/ccivil_03/Leis/L10165.htm >. Acesso em: 16 abr. 2015.

BURGWAL, D. V. de; VIEIRA, R. J. O. Environmental Disclosure Determinants in Dutch Listed Companies. In: Revista Contabilidade e Finanças, USP, São Paulo, v. 25, n. 64, p. 60-78, jan./fev./mar./abr. 2014.

CALIXTO, L.; BARBOSA, R. R.; LIMA, M. B. Disseminação de informações ambientais voluntárias: relatórios contábeis versus internet. Revista Contabilidade e Finanças, p. 84-95, Edição 30 anos do Doutorado, 2007. Disponível em: <http://www.scielo.br/pdf/rcf/ v18nspe/a08v18sp.pdf>. Acesso em: 13 jan. 2016.

CARREIRA, F; DAMIÃO, A.; ABREU, R.; DAVID, F. Environmental Disclosure: From the Accounting to the Report Perspective. In: Proceedings of the $16^{\text {th }}$ International Conference on Enterprise Information Systems, pages 496-501, 2014.

COMITÊ DE PRONUNCIAMENTOS CONTÁBEIS (CPC). Pronunciamento Conceitual Básico (R1): Estrutura Conceitual para Elaboração e Divulgação de Relatório Contábil-Financeiro. Brasília: CPC. 2011. Disponível em: < http://static.cpc.mediagroup.com.br/Documentos/147_CPC00_R1.pdf>. Acesso em: 15 set. 2015.

DYE, R. A. An evaluation of "essays on disclosure" and the disclosure literature in accounting. Journal of Accounting and Economics, v. 32, n. 1, p. 181-235, 2001.

FERNANDES, S. M. Fatores que influenciam o disclosure ambiental: um estudo nas empresas brasileiras no período de 2006 a 2010. Disponivel em: <http://dialnet.unirioja.es/servlet/articulo?codigo=4655880>. 2013. Acesso em: 13 jan. 2016.

GODOI, A. F. de. Contabilidade Ambiental: Um estudo do disclosure de informações ambientais, das empresas dos setores de alto impacto ambiental, integrantes do ISE - Índice de Sustentabilidade Empresarial. 2011. 181. Dissertação (Mestrado em Ciências Contábeis e Atuariais) - Pontifícia Universidade Católica de São Paulo, São Paulo, 2011.

IUDÍCIBUS, S. Teoria da Contabilidade. 8. ed. São Paulo: Atlas, 2006.

JENKINS, H.; YAKOVLEVA, N. Corporate social responsibility in the mining industry: Exploring trends in social and environmental disclosure. Journal of cleaner production, v. 14, n. 3, p. 271-284, 2006.

KRONBAUER, C. A.; SILVA, M. M. da. Disclosure Ambiental: análise do grau de evidenciação nas demonstrações contábeis das empresas de transporte. 2012. Disponível em: < http://www.epublicacoes.uerj.br/index.php/rcmccuerj/article/view/5372/3959>. Acesso em: 13 jan. 2016.

LIMA, D. V. de; VIEGAS, Waldyr. Tratamento contábil e evidenciação das externalidades ecológicas. 2002. Disponível em: <http:// www.scielo.br/pdf/rcf/v13n30/v13n30a04.pdf>. Acesso em: 13 jan. 2016.

MARTINS, G. de A.; THEÓPHILO, C. R. Metodologia da Investigação Cientifica para Ciências Sociais Aplicadas. 2. ed. São Paulo: Atlas, 2009.

NEU, D.; WARSAME, H.; PEDWELL, K. Managing public impressions: environmental disclosures in annual reports. Accounting, organizations and society, v. 23, n. 3, p. 265-282, 1998. 
NOR, M. N.; BAHARI, N. A. S.; ADNAN, N. A.; KAMAL, S. M. Q. A. S.; ALI, I. M. The Effects of Environmental Disclosure on Financial Performance in Malaysia. In: Procedia Economics and Finance, 35, 117 - 126, 2016

OLIVEIRA, A. F. de; MACHADO, D. G.; BEUREN, I. M. Evidenciação ambiental de empresas de setores potencialmente poluidores listadas no Índice de Sustentabilidade Empresarial (ISE). Revista de Gestão Social e Ambiental - RGSA, São Paulo, v. 6, n. 1, p. 20-37, jan./ abr. 2012.

PIRES, C. B.; SILVEIRA, F. C. da S. A evolução da evidenciação das informações ambientais de empresas do setor de celulose e papel: uma análise de conteúdo das notas explicativas e relatórios de administração. 2008. Disponível em: <http://www.seer.ufrgs.br/ConTexto/article/view/11104/6591>. Acesso em: 13 jan. 2016.

RAFFAELLI, S. C. D.; AMARO, H. D.; SILVA, W. V.; ALMEIDA, L. B. Alisamento de resultados e disclosure ambiental: uma investigação no setor de siderurgia e metalurgia brasileiro. 2014. Disponivel em: <http://www.atena.org.br/revista/ojs2.2.306/index.php/ Ambiente/article/view/1916/1751>. Acesso em: 13 jan. 2016

RIBEIRO, A. M.; BELLEN, H. M. V.; CARVALHO, L. N. G. de. Regulamentar faz diferença? O caso da evidenciação ambiental. Revista de Contabilidade \& Finanças. São Paulo, v. 22, n. 56, maio/ago. 2011.

RICHARDSON, R. J. Pesquisa social: métodos e técnicas. 3. ed. São Paulo: Atlas, 1999.

ROSA, F. S.; FERREIRA, A. C. S.; ENSSLIN, S. R.; ENSSLIN, L. Evidenciação ambiental (EA): Contribuição da metodologia multicritério para identificação dos aspectos financeiros para a gestão ambiental. 2010. Disponível em: <www.spell.org.br/documentos/ download/8153>. Acesso em: 13 jan. 2016.

ROVER, S.; BORBA, J. A.; MURCIA, F. D. R. Características do Disclosure Ambiental de Empresas Brasileiras Potencialmente Poluidoras: Análise das Demonstrações Financeiras e dos Relatórios de Sustentabilidade do Período de 2005 a 2007. Contextus Revista Contemporânea de Economia e Gestão, Fortaleza, v. 7, n. 1, jan./jun. 2009.

SILVA, M. N.; LIMA, J. A. S. O.; FREITAS, M. A. L.; FILHO, L. L. S.; LAGIOIA, U. C. T. Determinantes do disclosure ambiental nos relatórios de empresas listadas na Bovespa. 2015. Disponivel em: <http://dialnet.unirioja.es/servlet/articulo;jsessionid=47AD2001369F4DC24856A0ECA2D6F7A4.dialnet02?codigo=5105581>. Acesso em: 13 jan. 2016.

VERRECCHIA, R. E. Essays on disclosure. Journal of accounting and economics, v. 32, n. 1, p. 97-180, 2001. 